\title{
BIM in Oil, Gas, and Petrochemical Projects
}

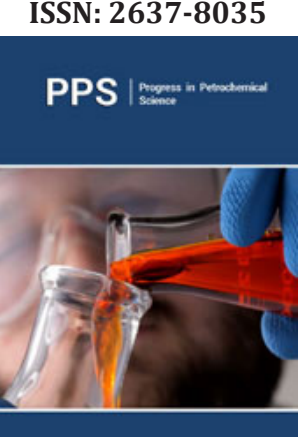

*Corresponding author: Hasheminasab H,SEPID, Sustainability Assessment Group, Iran

Submission: 侮 September 29, 2020

Published: 毕 December 21, 2020

Volume 3 - Issue 5

How to cite this article: Hasheminasab H. BIM in Oil, Gas, and Petrochemical Projects. Progress Petrochem Sci. 3(5). PPS. 000574. 2020

DOI: 10.31031/PPS.2020.03.000574

Copyright@ Hasheminasab H, This article is distributed under the terms of the Creative Commons Attribution 4.0 International License, which permits unrestricted use and redistribution provided that the original author and source are credited.

\author{
Hasheminasab $\mathrm{H}^{1 *}$ \\ ${ }^{1}$ SEPID, Sustainability Assessment Group, Iran
}

\section{Introduction}

The main function of Building Information Modeling (BIM) is to virtually model a construction project to reduce unforeseen circumstances. The applications of BIM in different construction fields and various engineering disciplines have grown over time. Based on existing literature, the percentage of North American construction companies that are using BIM software has grown from 28\% in 2007 to $71 \%$ in 2012. Based on 2012 statistics, contractors are using BIM 4\% more than architects and 7\% more than engineers Figure 1.

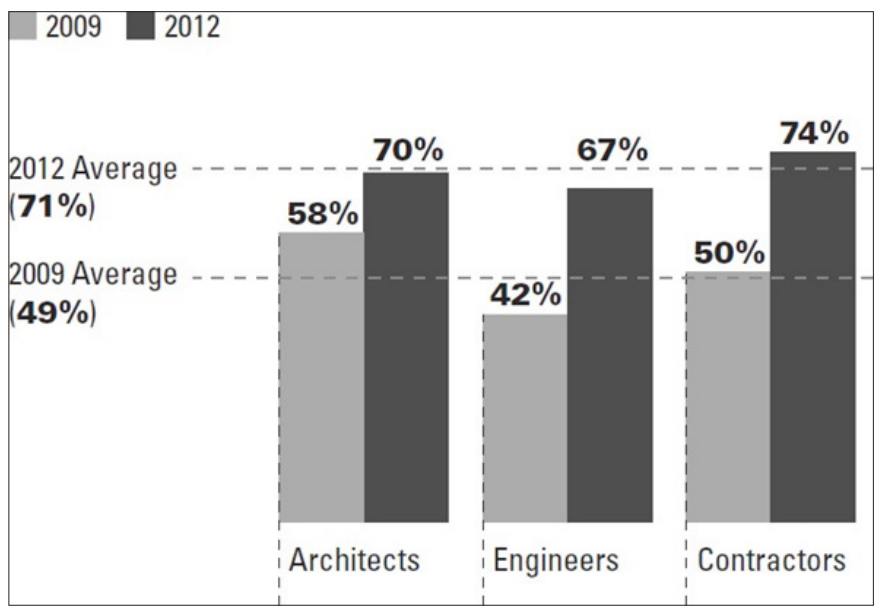

Figure 1: North America construction companies using BIM [1].

BIM deals with multiple stakeholders from owners, contractors, designers, and consultants to operators, analyzers, and programmers. Sun shading, daylighting, lifecycle assessment, energy modeling, and water usage calculation are some examples of the lateral analyzes covered by BIM software. The construction industry has benefited from BIM in the following ways:

A. Improve interoperability and communication between engineering disciplines, owners, vendors, and manufacturers

B. Reduce construction as well as operation cost

C. Improve constructability and unforeseen clashes

D. Reduce reworks and construction time and improve productivity

E. Reduce drawing ambiguities and site's Technical Queries (TQs)

F. Improve the accuracy of cost estimation

G. Reduce document version control and provide a clarified environment

H. Facilitate sustainability and energy-related assessments and calculations

I. Realize the life-cycle approach in all phases of projects

J. Streamline Facilities Management (FM) practices and procedures

In terms of easier communication, the improvement in interoperability and communication becomes even more crucial in mega projects in which a multitude of stakeholders and 
disciplines are involved. For instance, various engineers need to collaborate for a building project from architects to structural designers and MEP engineers, who have to work together on a single model simultaneously. This collaboration would be even more important when a change is requested. Every modification needs to be traceable by the author's name, date, and department. Every change may influence another department or may cause clashes or constructability difficulties in the final model which needs to be taken into account in the 3D model Figure 2 .

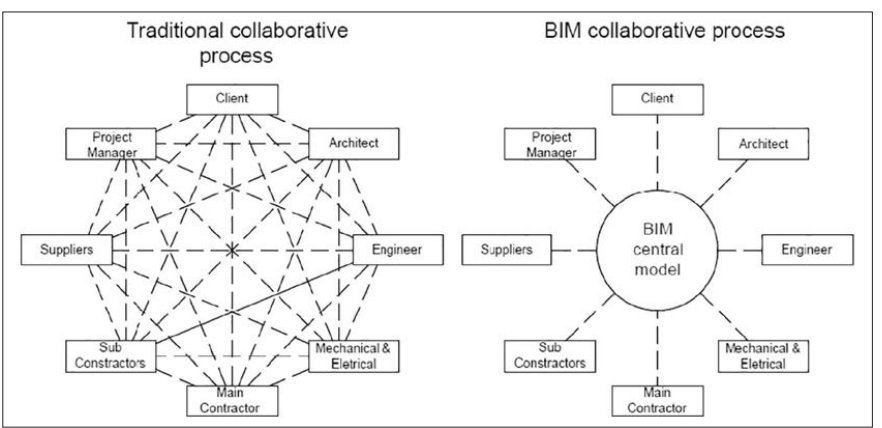

Figure 2: Collaboration in traditional vs. BIM processes [2].

In Oil, Gas, and Petrochemical (OGP) projects the problems that could arise from lack of proper communication, are much more complicated due to the following reasons:

A. The more diverse range and a deeper involvement of engineering disciplines, as well as other stakeholders, such as MC, licensor, manufacturer, vendor, supplier, customs office, and other local authorities such as environmental agencies, transportation departments, etc.

B. Due to the high cost of OGP projects, productivity improvement will result in more significant savings. Depending on the means of improving productivity, costs may be decreased in construction or operation phases.

C. Constructability, works sequence, and the site layout is more complicated in OGP projects and needs to be clarified in accordance with the requirements and interests of various stakeholders as well as operating the company's processes and assets and lessons learned.

D. More complex work sequence and reciprocal engineering feeding in OGP projects need more collaboration in particular, which means, excessive modifications will lead to more extensive rework.

E. Since OGP projects' documents and drawings include more details that are provided by various parties, ambiguity is more likely to happen. Obviously, the ambiguity will result in more TQs and reduce the productivity and speed of construction activities. This is why a real 3D model would result in a clearer and more accurate environment.
F. In OGP projects more construction and operation cost is involved. Also, higher risks and hazards are to be dealt with; this would require more elaborate and accurate assessment and estimation.

G. One of the important activities in OGP projects is vendor document control, which takes a lot of engineering man-hour. A more comprehensive and realistic model can improve mutual understanding, reduce the number of comments, and result in lower document versioning.

BIM in OGP projects has been continuously developed and improved via various software. Among this group of software, the likes of Revit and Navisworks are commonly used both for building and OGP projects. Meanwhile, there is other software that is developed exclusively for industrial projects such as OGP. Here are some of the tools that are used in OGP projects for BIM purposes:

A. AVEVA: PDMS, Everything 3D (E3D), BOCAD, etc.

B. Bentley: PDS, Plant Design, Intergraph Smart Plant 3D, etc.

C. Autodesk: Revit, AutoCAD Plant 3D, Navisworks, etc.

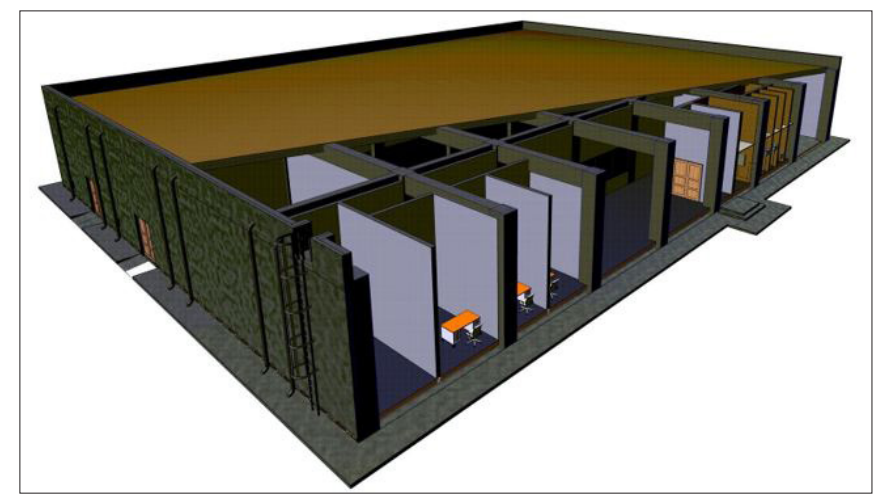

Figure 3: Sample 3D model exported from Revit.

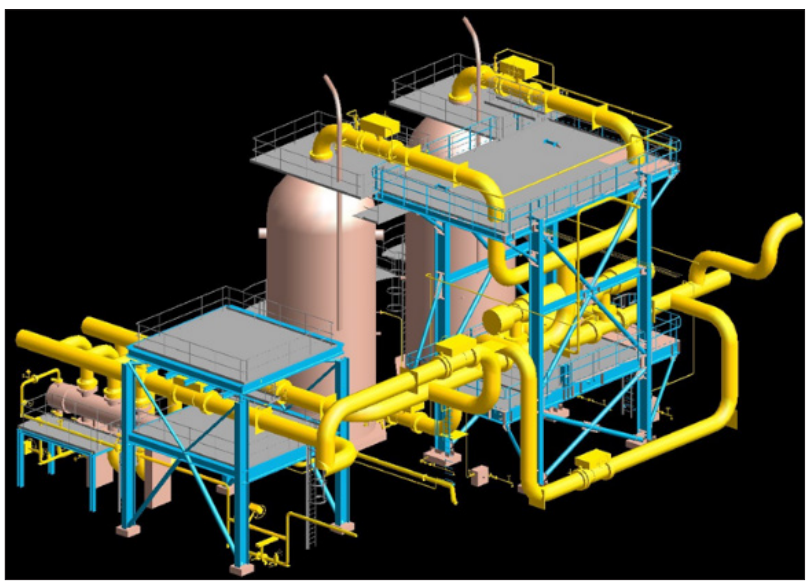

Figure 4: An access platform and equipment modeled in PDMS.

AVEVA has been developed in the UK and is widely used for OGP projects and plays a pivotal role in Middle Eastern projects as it is 
demanded by owners. This platform contains many engineering modules and has been continuously improved from PMDMS 11 which was applicable for windows XP-32bit to PDMS 12 which was capable of working on Windows 64bit, and finally, E3D which is an integrated AVEVA solution for OGP projects. AVEVA's integrated solution can be used by every engineering discipline. This group of software has a large market share and has the highest prices compared to its competitors Figure $3 \& 4$. The AVEVA integrated solution is designed to be used by all engineering disciplines by using a single database. Every discipline connects to the project database and depending on their authorization level, can read, write, and add comments on different parts of the virtual project model Figure 5.

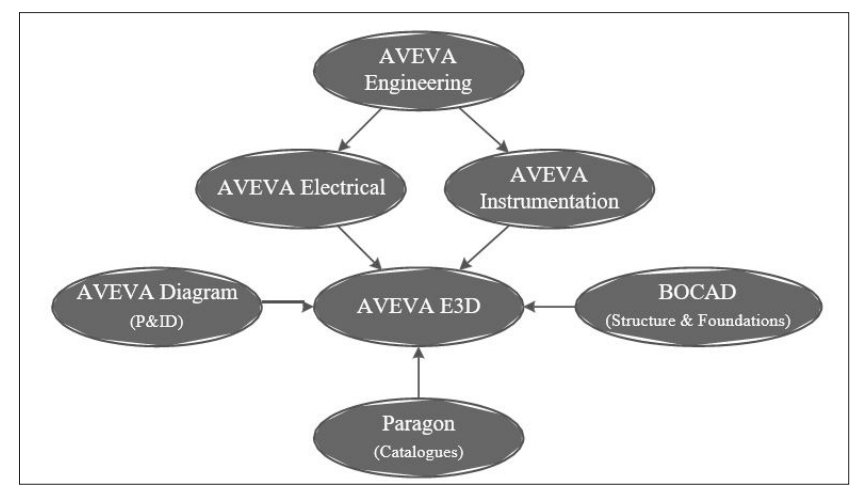

Figure 5: AVEVA integrated solution map.
Bentley is an American BIM software that comprises multiple engineering modules. The old version of the software was PDS which was gradually improved to Smart plant 3D. Despite its high reputation and its many fascinating features that could be used for OGP projects, from the vantage point of the author, Bentley has not been able to gain the momentum that it deserves in OGP projects. In addition to AVEVA and Bentley, Autodesk has developed a range of user-friendly and popular software from AutoCAD to Revit and Plant 3D. "Navisworks" as a popular 3D navigation software has been developed by Autodesk which can import from most BIM 3D software, including Bentley and AVEVA. With the introduction of Industry Foundation Class (IFC) universal formats, the future will be even more collaborative and productive $[1,2]$.

\section{References}

1. Carvalho JP, Bragança L, Mateus R (2019) Optimising building sustainability assessment using BIM. Automation in Construction 102: 170-182.

2. (2012) The business value of BIM in North America: Multi-year trend analysis and user ratings (2007-2012), McGraw Hill Construction, Smart Market Report, USA. 